\title{
The Role of Concha Bullosa in Chronic Rhinosinusitis: A Single Centre Study
}

Dr. Atiur Rahman ${ }^{1 *}$, Dr. Md. Sazzadul-haq ${ }^{2}$, Dr. Md. Raqibul Alam ${ }^{3}$

${ }^{1}$ Assistant Professor, Department of ENT, Shaheed Monsur Ali Medical College and Hospital, Uttara, Dhaka, Bangladesh

${ }^{2}$ Assistant Professor, Department of ENT, Munno Medical College and Hospital, Manikganj, Bangladesh

${ }^{3}$ Assistant Professor, Department of ENT, Sheikh Hasina Medical College and Hospital, Tangail, Bangladesh

*Corresponding Author: Dr. Atiur Rahman

Assistant Professor, Department of ENT, Shaheed Monsur Ali Medical College and Hospital, Uttara, Dhaka, Bangladesh

\section{Article History}

Received: 04.12 .2021

Accepted: 09.01.2022

Published: 17.01.2022

\begin{abstract}
Introduction: Chronic rhinosinusitis (CRS) is a common and persistent illness that otorhinolaryngologists encounter commonly. It is an important cause of morbidity and accounts for major loss of income. Anatomical variations of the lateral wall of the nose have been reported which can predispose to CRS. The aim of the present study was to determine the percentage of concha bullosa in patients with CRS and to ascertain its relationship with chronic rhinosinusitis. Aim of the study: To determine the percentage of concha bullosa in patients with chronic rhinosinusitis and to determine the relationship between concha bullosa and chronic rhinosinusitis. Methods: This was a hospital based prospective one-year study done during the period from June 2019 to December 2020 was conducted at the outpatient department of ENT, Shaheed Monsur Ali Medical College and Hospital, Uttara, Dhaka, Bangladesh. Sample size in this study were selected 57 patients. Result: Of the 57 patients in our study, 21 were males and 36 were females (Figure-1). Of these $36.84 \%$ male patients 21 showed concha bullosa and of the 63.84 female patients 326 showed concha bullosa on CT nose and PNS and DNE. The most common age group showing concha bullosa was 21-30 years 23(40.35\%) (Table 1). The most common symptom found in our study was headache in $57(100.00 \%)$. The next commonly occurring symptom was nasal block 51(89.47\%) followed by nasal discharge or nasal purulence 48(84.21\%). DNE and CT scan of nose and paranasal sinuses (coronal and axial) were studied for the evaluation of concha bullosa in our patients of CRS. Concha bullosa was noted in $33(57.89 \%)$ patients having unilateral and bilateral presentations. Conclusion: Concha bullosa is one of the most common anatomical variations of the lateral wall of the nose. The presence of concha bullosa plays a significant role in the development of chronic rhinosinusitis particularly in chronic maxillary sinusitis.
\end{abstract}

Keywords: Chronic rhinosinusitis, Concha bullosa, Diagnostic nasal endoscopy, Computed tomography.

\section{INTRODUCTION}

Chronic rhinosinusitis is a complex disease that has previously been used to describe conditions ranging from unilateral single sinus disease, odontogenic sinusitis, fungal sinusitis, to widespread airway inflammation. The currently recognized definition of primary CRS is represented by chronic inflammation of the paranasal sinuses. In this discussion, primary CRS refers to a sinus condition in which no obvious secondary pathoetiologic event is occurring (ie fungal ball, neoplasia, odontogenic or immunodeficiency). Classically, primary CRS has been separated into two major subtypes based upon phenotypic appearance; CRS with nasal polyps (CRSwNP) and CRS without nasal polyps (CRSsNP) [1, 2]. In the USA the prevalence of CRS has been estimated to be $14 \%$ of the population. In 1979, Albegger calculated the prevalence of rhinosinusitis in general population to range from $32 \%$ in young children to $5 \%$ in adults [3]. However no conclusive studies are available about the prevalence of rhinosinusitis in Bangladesh. Chronic headache is one of the common symptoms which is distressing to both the patient as well as the physician. It becomes difficult to ascertain the nature of headache owing to multiple factors such as self- administered medications by the patient, vague nature of the

Copyright $(9) 2022$ The Author(s): This is an open-access article distributed under the terms of the Creative Commons Attribution 4.0 International License (CC BY-NC 4.0) which permits unrestricted use, distribution, and reproduction in any medium for noncommercial use provided the original author and source are credited. 
headache etc. The investigative modalities for evaluation of headache available to an ENT surgeon are many, such as plain X-ray, CT scan of nose and paranasal sinuses (PNS) and diagnostic nasal endoscopy. There are several anatomical variations associated with the lateral wall of the nose [4]. Concha bullosa is defined as the pneumatisation of the middle turbinate. More commonly concha bullosa contains a single air cell. Multiple air cells are relatively rare. Based on the type of pneumatisation pattern they can be further classified as lamellar, bulbous and extensive [5]. It has been suggested that the presence of concha bullosa may attribute to the development of CRS. Clark et al found a higher incidence of the bulbous portion of the middle turbinate in patients with chronic rhinosinusitis [6]. On the contrary Yousem et al., did not find any increase in the incidence of chronic rhinosinusitis in the presence of concha bullosa. Therefore, there is a need to study the relationship between concha bullosa in patients with chronic rhinosinusitis [7]. To determine the percentage of concha bullosa in patients with chronic rhinosinusitis and to determine the relationship between concha bullosa and chronic rhinosinusitis

\section{Methodology \& Materials}

This was a hospital based prospective one-year study done during the period from June 2019 to December 2020 was conducted at the outpatient department of ENT, Shaheed Monsur Ali Medical College and Hospital, Uttara, Dhaka, Bangladesh. Sample size in this study were selected 57 patients.57 consecutive patients presenting with complaints related to CRS were selected for the study. Patients were clinically diagnosed as chronic rhinosinusitis based on the criteria set forth by the task force on rhinosinusitis.

\section{Inclusion criteria}

Inclusion criteria were those who were consenting for the study, patients willing to undergo CT scan of nose and paranasal sinuses and nasal endoscopy, patients satisfying the clinical criteria by the task force on rhinosinusitis and patients above the age of 10 years.

\section{Exclusion criteria}

Exclusion criteria were history of previous nasal surgery, history of nasal trauma, patients with tumours of the nose and paranasal sinuses, pregnant women, patients not fit for CT scan and patients with allergy to xylocaine anaesthesia.

\section{Method of data collection}

After taking an informed written consent, 100 patients above the age of 10 years clinically diagnosed as chronic rhinosinusitis according to the criteria of task force on rhinosinusitis were included in the present study. Using $4 \%$ topical xylocaine as anaesthesia and decongestion using $1 \mathrm{ml}$ topical adrenaline, DNE was done to study the presence of concha bullosa. These patients underwent a CT scan which enabled us to study the presence of concha bullosa radiologically (Figures 1 and 2).

Changeable image....

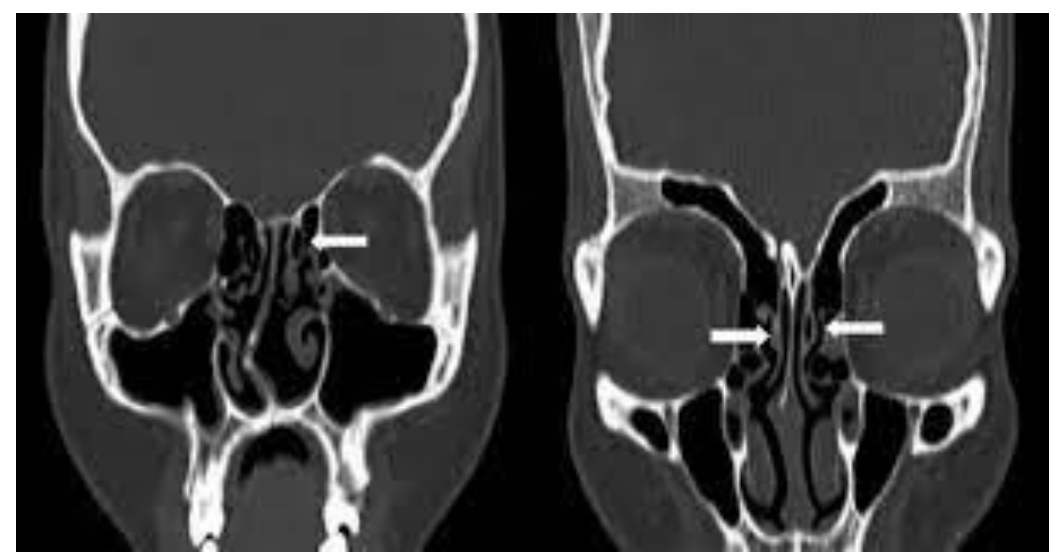

Figure 1: Computed tomography scans showing concha bullosa. (a) unilateral concha bullosa and (b) bilateral concha bullosa

Changeable image.... 


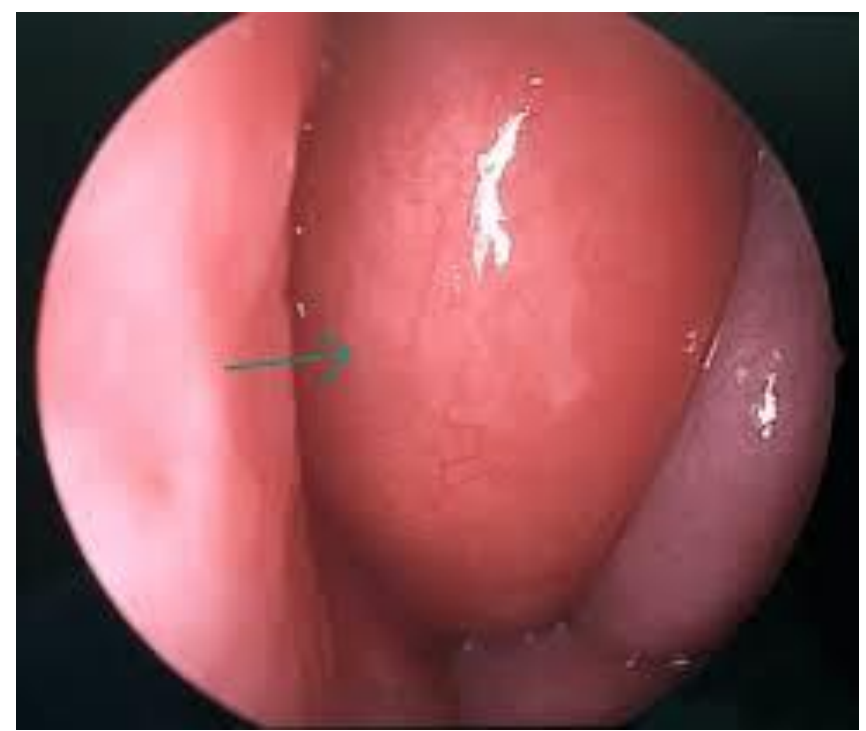

Figure 2: Endoscopic picture showing concha bullosa

All procedures performed in the study were in accordance with the ethical standards of the institutional and/or national research committee. Data was collected and tabulated in an excel sheet. Results presented as proportions and percentages. Chi square test was applied for qualitative data. A p value

\section{RESULTS}

Of the 57 patients in our study, 21 were males and 36 were females (Figure-1). Of these $36.84 \%$ male patients 21 showed concha bullosa and of the 63.84 female patients 326 showed concha bullosa on CT nose and PNS and DNE. The most common age group showing concha bullosa was 21-30 years 23(40.35\%) (Table 1). The most common symptom found in our study was headache in $57(100.00 \%)$. The next commonly occurring symptom was nasal block $51(89.47 \%)$ followed by nasal discharge or nasal purulence $48(84.21 \%$ ) (Table 2). DNE and CT scan of nose and paranasal sinuses (coronal and axial) were studied for the evaluation of concha bullosa in our patients of CRS. Concha bullosa was noted in 33(57.89\%) patients having unilateral and bilateral presentations. The concha bullosa was noted more commonly on the right side as seen on nasal endoscopy and computed tomography. Suitable statistical analysis was applied and the association between the presence of concha bullosa and occurrence of chronic rhinosinusitis was determined. A statistically significant correlation was noted between presence of concha bullosa and chronic maxillary sinusitis (i.e. p value <0.05) (Table 3). No statistical significance was noted between presence of concha bullosa and chronic frontal and ethmoid sinusitis (Table 4 and 5).

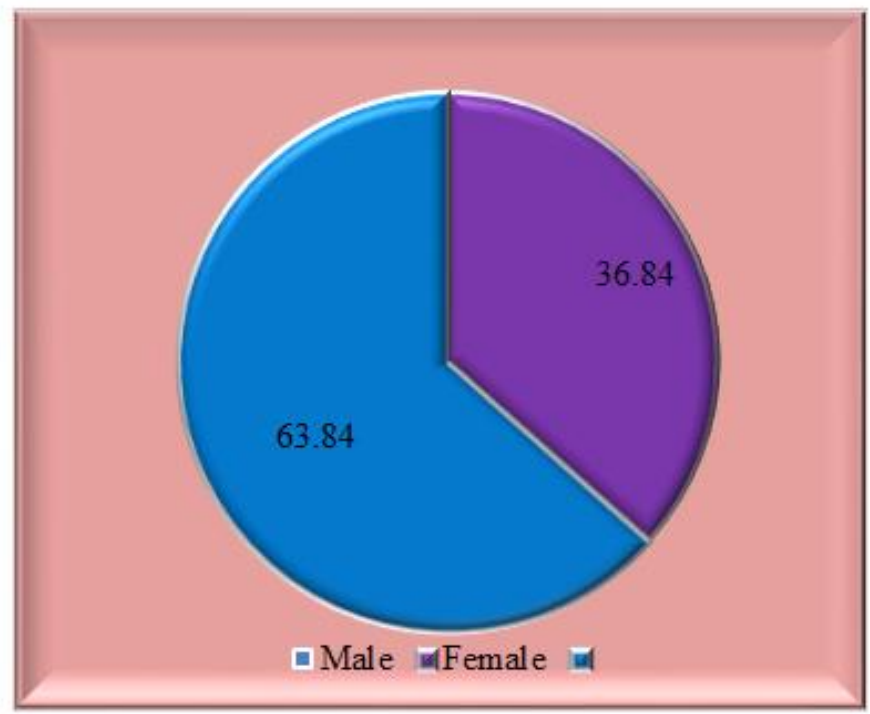

Figure-1: Gender distribution of study patients $(\mathrm{N}=57)$ 
Table 1: Age distribution of patients with concha bullosa $(\mathrm{N}=57)$

\begin{tabular}{|l|l|l|}
\hline Age (in years) & Frequency & Percentage \\
\hline $11-20$ & 9 & 15.79 \\
\hline $21-30$ & 23 & 40.35 \\
\hline $31-40$ & 15 & 26.32 \\
\hline $41-50$ & 7 & 12.28 \\
\hline$>50$ & 3 & 5.26 \\
\hline Total & 57 & 100 \\
\hline
\end{tabular}

Table 2: Symptomatology of study patients $(\mathrm{N}=57)$

\begin{tabular}{|l|l|l|}
\hline Symptoms & Frequency & Percentage \\
\hline Headache & 57 & 100.00 \\
\hline Nasal block & 51 & 89.47 \\
\hline Nasal discharge & 48 & 84.21 \\
\hline Facial fullness & 30 & 52.63 \\
\hline Cough & 22 & 38.60 \\
\hline Halitosis & 15 & 26.32 \\
\hline
\end{tabular}

Table 3: Association between concha bullosa and chronic maxillary sinusitis $(\mathrm{N}=57)$

\begin{tabular}{|l|l|l|l|l|l|l|}
\hline \multirow{2}{*}{ Variables } & \multicolumn{2}{l|}{$\begin{array}{l}\text { Chronic maxillary } \\
\text { sinusitis present }\end{array}$} & \multicolumn{2}{l}{$\begin{array}{l}\text { Chronic maxillary } \\
\text { sinusitis absent }\end{array}$} & \multirow{2}{*}{ Potal } \\
\cline { 2 - 6 } & $\mathbf{N}$ & $\mathbf{\%}$ & $\mathbf{N}$ & $\mathbf{\%}$ & \\
\hline Concha bullosa present & 19 & 46.34 & 14 & 87.50 & 33 & 57.89 \\
\hline Concha bullosa absent & 22 & 53.66 & 2 & 12.50 & 24 & 42.11 \\
\hline Total & 41 & 100.00 & 16 & 100.00 & 57 & 100.00 \\
\hline
\end{tabular}

Table 4: Association between concha bullosa and chronic frontal sinusitis ( $N=57)$

\begin{tabular}{|l|l|l|l|l|l|l|}
\hline \multirow{2}{*}{ Variables } & Chronic frontal sinusitis present & Chronic frontal sinusitis absent & Total & Percentage \\
\cline { 2 - 6 } & $\mathbf{N}$ & $\mathbf{\%}$ & $\mathbf{N}$ & \% & & \\
\hline $\begin{array}{l}\text { Concha bullosa } \\
\text { present }\end{array}$ & 15 & 40.54 & 9 & 45.00 & 24 & 42.11 \\
\hline $\begin{array}{l}\text { Concha bullosa } \\
\text { absent }\end{array}$ & 22 & 59.46 & 11 & 55.00 & 33 & 57.89 \\
\hline Total & 37 & 100.00 & 20 & 100.00 & 57 & 100.00 \\
\hline
\end{tabular}

Table 5: Association between concha bullosa and chronic ethmoid sinusitis $(\mathrm{N}=57)$

\begin{tabular}{|l|l|l|l|l|l|l|}
\hline \multirow{2}{*}{ Variables } & $\begin{array}{l}\text { Chronic ethmoid sinusitis } \\
\text { present }\end{array}$ & $\begin{array}{l}\text { Chronic ethmoid sinusitis } \\
\text { absent }\end{array}$ & Total & Percentage \\
\cline { 2 - 6 } & $\mathbf{N}$ & $\mathbf{\%}$ & $\mathbf{N}$ & $\mathbf{\%}$ & \\
\hline Concha bullosa present & 13 & 32.50 & 7 & 41.18 & 20 & 35.09 \\
\hline Concha bullosa absent & 27 & 67.50 & 10 & 58.82 & 37 & 64.91 \\
\hline Total & 40 & 100.00 & 100.00 & 57 & 100.00 \\
\hline
\end{tabular}

\section{DISCUSSION}

Nasal endoscopy in association with computed tomography of nose and PNS provides a more specific and accurate approach to sino nasal diseases. The success rate of FESS for treating CRS has been documented as $80 \%$ to $95 \%$ by various researchers $[8,9]$. Such high rates are possible only by accurate preoperative localization of the disease. It is advisable to combine both these modalities in the preoperative diagnosis and ascertaining the anatomical variations of lateral wall of nose which account for the sino nasal disease. In our study of 100 patients with chronic rhinosinusitis, the proportion of female patients $60 \%$ was higher than male patients. A similar pattern was reported in several other studies $[10,11]$. Although a similar pattern of gender distribution has been noted in these studies, no specific reason has been reported for the same. The most common age group in our study was 21-30 years which included 22\% patients. In a similar study conducted by Tuli et al., on 50 patients, the most commonly affected age group was between 21-35 years $30 \%$ [12]. Headache was the most common symptom noted in our study $92 \%$ followed by nasal block $86 \%$. The next frequently occurring complaint was nasal discharge or nasal purulence present in $82 \%$ cases (Table 2). In a study by 
Wani et al., headache was the most common complaint seen in $90 \%$ of the patients, followed by nasal discharge $86.6 \%$ and nasal obstruction $85.33 \%$ [13]. These results were in accordance with the results of our present study. Concha bullosa was seen in $44 \%$ of our patients showing unilateral and bilateral presentations. Our study showed higher incidence of concha bullosa in the age group of 21 to 30 years. In a study done by Hatipoglu et al., the mean age of patients was 30 years [14]. Our study showed a statistically significant association between presence of concha bullosa and maxillary sinusitis with a p value of $<0.05$ (Table 3 ). This could be attributed to the blocking of ostiomeatal unit resulting in obstruction to maxillary sinus outflow. No significant association was noted between presence of concha bullosa and chronic frontal and ethmoid sinusitis (Tables 4 and 5). Stammberger et al., state that pneumatisation process apparently begins in middle age in some patients when there may be a renewed spurt of growth activity [15]. Reda et al., in his study showed inflammatory disease of the sinuses in $71.7 \%$ patients with concha bullosa and $57.7 \%$ patients without concha bullosa [16]. Maru et al., showed an association between sinusitis and concha bullosa in his studies especially with pneumatisation involving anterior end of middle turbinate [17]. In a study done by Prinja et al., a significant association was noted between presence of concha bullosa and occurrence of chronic maxillary sinusitis [18]. Our results were in accordance with these studies showing a statistical significance between presence of concha bullosa and chronic maxillary sinusitis.

\section{Limitations of the study} community

The study was conducted in a single hospital with small sample size. So, the results may not represent the whole

\section{CONCLUSION AND RECOMMENDATIONS}

Pneumatization of the middle turbinate which is referred to as concha bullosa, is one of the most common anatomical variations of the lateral wall of the nose. In our study an attempt was made to study the percentage of CRS patients having concha bullosa and if this had any association with the occurrence of CRS. We found a statistically significant relation between the presence of concha bullosa and occurrence of CRS, particularly in chronic maxillary sinusitis. But no such association was noted for chronic frontal or ethmoid sinusitis.

Funding: No funding sources

Conflict of interest: None declared

Ethical approval: The study was approved by the Institutional Ethics Committee.

\section{REFERENCES}

1. Fokkens, W., Lund, V., \& Mullol, J. (2007). European position paper on R, nasal polyps g. European position paper on rhinosinusitis and nasal polyps 2007. Rhinol Suppl, 20, 1-136.

2. Fokkens, W. J., Lund, V. J., Hopkins, C., Hellings, P. W., Kern, R., Reitsma, S., ... \& Witterick, I. (2020). European position paper on rhinosinusitis and nasal polyps 2020. Rhinology, 58, I-+.

3. Zinreich, S., Albayram, S., Benson, M., \& Oliverio, P. (2003). The ostiomeatal complex and functional endoscopic surgery. In: Som, P., ed. Head and neck imaging. 4th ed. St Louis: Mosby; 149-173.

4. Arslan, H., Aydınlıoğlu, A., Bozkurt, M., \& Egeli, E. (1999). Anatomic variations of the paranasal sinuses: CT examination for endoscopic sinus surgery. Auris Nasus Larynx, 26(1), 39-48.

5. Basić, N., Basić, V., Jelić, M., Nikolić, V., Jukić, T., \& Hat, J. (1998). Pneumatization of the middle nasal turbinate: a CT study. Lijecnicki vjesnik, 120(7-8), 200-201.

6. Kangaroo SK, White PS, Lee MS. A randomized control trial of surgical task performance in frontal recess surgery: zero degree versus angled telescopes. Am J Rhinol. 2002;16(1):33-6.

7. Stammberger, H. (1986). Endoscopic endonasal surgery-concepts in treatment of recurring rhinosinusitis. Part II. Surgical technique. Otolaryngology-Head and Neck Surgery, 94(2), 147-156.

8. Kennedy, D. W. (1985). Functional endoscopic sinus surgery: technique. Archives of otolaryngology, 111(10), 643649.

9. Perez-Pinas, I., Sabate, J., Carmona, A., Catalina-Herrera, C. J., \& Jimenez-Castellanos, J. (2000). Anatomical variations in the human paranasal sinus region studied by CT. The Journal of Anatomy, 197(2), 221-227.

10. Zinreich, S. J., Mattox, D. E., Kennedy, D. W., Chisholm, H. L., Diffley, D. M., \& Rosenbaum, A. E. (1988). Concha bullosa: CT evaluation. Journal of computer assisted tomography, 12(5), 778-784.

11. Macdonald, K. I., McNally, J. D., \& Massoud, E. (2009). Quality of life and impact of surgery on patients with chronic rhinosinusitis. Journal of Otolaryngology--Head \& Neck Surgery, 38(2).

12. Tuli, I. P., Sengupta, S., Munjal, S., Kesari, S. P., \& Chakraborty, S. (2013). Anatomical variations of uncinate process observed in chronic sinusitis. Indian Journal of Otolaryngology and Head \& Neck Surgery, 65(2), $157-161$.

13. Wani, A. A., Kanotra, S., Lateef, M., Ahmad, R., Qazi, S. M., \& Ahmad, S. (2009). CT scan evaluation of the 
anatomical variations of the ostiomeatal complex. Indian Journal of Otolaryngology and Head \& Neck Surgery, 61(3), 163-168.

14. Hatipoglu, H. G., \& Cetin, M. A. (2005). Enis Yuksel from the Departments of Radiology and Ear, Nose and Throat Surgery (M.A.C.), Ankara Numune Research and Training Hospital, Ankara, Turkey; 145-149.

15. Stammberger, H. (1991). Functional Endoscopic Sinus Surgery. Philadelphia: B. C. Decker. 161-169.

16. ZANDI, B., DAVOUDI, M., \& Mirgholami, A. R. (2003). Concha Bullosa and Other Sino-Nasal Variants: Clinical and CT Correlation. Iranian J Radiology, 31-36.

17. Maru, Y. K., \& Gupta, V. (2001). Anatomic variations of the bone in sinonasal CT. Indian Journal of Otolaryngology and Head and Neck Surgery, 53(2), 123-128.

18. Prinja, S., Davessar, J., Singh, G., Kansal, L., \& Kaur, J. (2017). Role of concha bullosa in etiopathogenesis of chronic rhinosinusitis: a clinical study. Int J Contemporary Med Res, 4(3), 774-776. 